\title{
Risky Sexual Practices among Adolescents Living with HIV Accessing HIV and AIDS Care Services at Health Facilities in the Central Region of Uganda
}

\author{
Ntulume $\mathrm{CK}^{* 1,2}$ \\ ${ }^{1}$ Sim's Medical Centre, Kampala, Uganda
}

${ }^{2}$ Kyambogo University, Kyambogo, Uganda

${ }^{*}$ Corresponding author: Ntulume CK, Sim's Medical Centre, P.O. Box 2436, Kampala, Uganda, Tel: 256752546621, E-mail: cephasntulume@yahoo.com

Citation: Ntulume CK (2018) Risky Sexual Practices among Adolescents Living with HIV Accessing HIV and AIDS Care Services at Health Facilities in the Central Region of Uganda. J Aids Hiv Infec 4(1): 104.

doi: 10.15744/2454-499X.4.104

Received Date: April 04, 2018 Accepted Date: June 01, 2018 Published Date: June 04, 2018

\begin{abstract}
Background: Adolescents living with HIV in Uganda are sexually active just like their uninfected peers. With the availability of antiretroviral therapy (ART), the surviving population of adolescents prenatally infected with HIV is increasing and they are becoming sexually active.

Results: Overall, $47.7 \%$ of adolescents living with HIV have ever been in a sexual relationship with a higher likelihood among females (RR 1.51; $\mathrm{p}=0.0014)$. Peer pressure was the major cause of the sexual relationships (54.6\%). $16.6 \%$ of them had non penetrative sexual activities only. Those in urban areas had a higher likelihood of not engaging in sexual relationship than those from rural areas (RR $0.59 ; \mathrm{p}=0.0032)$. Over $35 \%$ of the respondents were sexually active with females showing a greater likelihood $(\mathrm{RR} 1.65 ; \mathrm{p}=0.0035)$. More to that those older than 17 years had a higher likelihood of being sexually active than those 17 years and younger (RR 3.64; p- value $=0.0000$ ). About $66.7 \%$ had disclosed their HIV status to sexual partners, $84.3 \%$ were of the same HIV status as their sexual partners $(\mathrm{p}=0.002) .36 \%$ of those who had not disclosed to their partners felt guilty. Males had a higher likelihood of having sexual partners of the same HIV status (RR 1.39; $\mathrm{p}=0.02$ ). Only $41.9 \%$ used condoms during last sexual activity and $87.2 \%$ had one sexual partner. About $33.6 \%$ had first sexual debut when they were below 15 years with (females $25.2 \%$, males $8.4 \%, p=0.87$ ).

Conclusions: Adolescents living with HIV were sexually active especially females, more in rural areas. There was low condom use which was likely to propagate the spread of HIV and AIDS in Uganda. This calls for reproductive health needs of adolescents living with HIV to be addressed and integrated into HIV care programs.

Keywords: Adolescents Lliving with HIV; Sexual Ppractices of Aadolescents Lliving with HIV; Disclosure of HIV positive status to sexual partner; adolescents living with HIV in Uganda; Adolescent Sexual and Reproductive Health

List of abbreviations: AIDS- Acquired Immune Deficiency Syndrome; ART- Antiretroviral Therapy; CI- Confidence Interval; H/C- Health Centre; HIV- Human Immunodeficiency Virus; IEC- Information Education and Communication; KI- Key Informant; OR- Odds ratio; RR- Relative Risk; STI- Sexually Transmitted Infections; UAIS- Uganda AIDS Indicator Survey; UDHS- Uganda Demographic Health Survey; UNESCO- United Nations Education Scientific and Cultural Organization; UNFPA- United Nations Fund for Population activities; WHO- World Health Organisation
\end{abstract}

\section{Introduction}

Human sexual practices refer to the manner in which humans experience and express their sexuality as people engage in a variety of sexual acts from time to time. They include conduct and activities which are intended to arouse the sexual interest of another and personal interactions between individuals and normally result in sexual arousal and physiological changes in the aroused person, some of which are pronounced while others are more subtle [1]. When we talk about sexual practices it could mean kissing, hugging, oral sex, vaginal sex, masturbation or any kind of sexual activity [2].

Researchers have been able to explore the sexual practices of young adults in various ways including onset of sexual activity, number of sexual partners, frequency of sex, participation in group sex, use of alcohol or other drugs preceding sexual activity, sex without contraception or a condom, sex with a prostitute, and consensual sex without knowing the disease status of one's partner [3].

Today, approximately 2.2 million adolescents (between a low estimate of 2.0 million and a high estimate of 2.5 million) aged 10-19 are living with HIV, and most of them do not know their status and globally, this breaks down to 1.3 million (1.2 million-1.5 million) adolescent girls and 870,000 (770,000-960,000) adolescent boys were In sub-Saharan Africa,1,870,000 adolescents living with HIV $37 \%$ boys and $63 \%$ girls [4]. 
The Uganda AIDS Indicator Survey (UAIS) 2011 asserts that, HIV prevalence among women and men aged 15-49 has increased from 6.4\% in the 2004-05 Uganda Health Surveillance and Behavioural Survey (UHSBS) to 7.3\% 2011 UAIS [5]. 3.7\% of young women and men age 15-24 are living with HIV. Among never-married youth who reported having sex in the past 12 months, $42 \%$ of women and $46 \%$ of men age 15-24 used a condom at last sexual intercourse being higher among those living in urban areas and those with secondary or higher education. In addition, only 12 to 13 percent of young women and men say they had sex before age 15 ; however, by age 18, 60 percent of young women and 47 percent of young men have initiated sexual activity [5].

Many adolescents living with HIV have had sex or intend to have sex in future. More to that nearly two-thirds desire to have sex. More than four-fifths have had sex, and about two-thirds of those who have had sex had consensual first sex [6]. They are also worried about infecting others. In another study conducted in Uganda it was found that, for perinatally infected adolescents who are sexually active 33 percent reported having had sexual intercourse. 73 percent of them had consensual first sex and only about one-third reported using a method to prevent HIV infection or re-infection at first sex [7].

With the increased availability of antiretroviral treatment (ART) surviving population of adolescents who were perinataly and those sexually infected with HIV is increasing rapidly [8]. These adolescents are exploring their sexuality wereby they are involved in relationships, some of which are discordant, others are sexually active and yet others are looking at having a successful sexual relationship in future including having children. Promoting safer sex practices and addressing their sexuality can allow adolescents living with HIV to live longer more meaningful and fulfiling lives [9].

\section{Statement of the problem}

Sexual behaviour of adolescents living with HIV is not substantially different from that of HIV-uninfected peers. With the highly active antiretroviral therapy, increasing number of children, infected prenatally, is surviving into adolescence and is becoming sexually active and need reproductive health services [10]. Most of them are engaged in unprotected sex, hence at risk of HIV re-infection \& transmission. In addition, there are programmatic gaps in addressing the sexual and reproductive health needs of adolescents living with HIV [8]. In a study done at Mildmay Uganda on adolescents living with HIV, out of the 20 pregnant girls, only $14 \%$ brought their sexual partners for HIV testing, $75 \%$ of the 200 sampled adolescents were not willing to disclose their HIV status to their sexual partners, $30 \%$ were not willing to have protected sex [11]. In view of the above, it was deemed necessary to conduct a study focusing on the sexual practices of adolescents living with HIV in order to find ways of addressing issues related to their sexual behaviours, hence the need for this study. Furthermore, more research should be developed to study the subjective experience of these adolescents' sexuality and its impact on sexual experience in this population [12].
Aims
1. To determine whether adolescents living with HIV disclose their HIV status to their sexual partners
2. To identify factors that associated with sexual activity among adolescents living with HIV.
3. To find out if these adolescents practice safe sex.
4. To determine age at first sexual debut among adolescents living with HIV.

\section{Summary of existing literature}

For any child the transition to adulthood is fraught with challenges as young teens are expected to define their identities, make plans for the future, interact with peers, deal with their sexuality. It is particularly important that the hopes and dreams of adolescents living with HIV are nurtured and reinforced to help them realise their full potential and to impart in them a sense of responsibility for maintaining their own health and that of others [9]. In one study done on adolescents living with HIV, many of the respondents were determined not to let HIV alter their lives but they faced particular challenges around diagnosis and disclosure. For a small number of female respondents, being in a relationship where their partner is unaware of a respondent's HIV status mitigates opportunities for safer sex practices where the partner does not consider condom use a necessity [13].

Disclosure to sexual partners: Many sexually active adolescents express concern for their partners' health but fear rejection and accusations of being unfaithful if they disclose but hard as it is for an adolescent to tell his or her partner that he or she is living with HIV, it is the right thing to do. The best way to safeguard his or her health and that of his or her partner and more to that, they might find that their partner is accepting and supportive were some teenagers say that they experienced a sense of relief and felt much closer to their partners, for others it meant the realisation that their HIV status would never be accepted within a particular relationship [13]. This puts young people at a greater risk of transmitting HIV to others [14].

In Botswana, as a result of Teen Club, members have expressed a need for information and guidance on healthy disclosure as very few teens have admitted to disclosing their sero-status to a friend or romantic partner and that they require information about healthy decision-making and how it relates to their infection in order to live positively and avoid treatment failure [15]. Disclosing sero-status was one of the greatest fears of the adolescents (51 percent feared disclosing their status to friends). Qualitative data however, suggested that even in the event of disclosure, the partners do not mind having or continuing the relationship, even if they are discordant. In addition, 41 percent of the sexually active female adolescents had ever been pregnant, almost threequarters of them kept the pregnancy [7]. 
Safer sex practices: Abstinence is the safest course but it may not be of any help to those who wish to have sex or are forced to do so. This is an option that many young people choose, but others don't want to wait to have sex and will act on the sexual feelings that are natural and normal in puberty. This is why it is so important to encourage young people to take responsibility for safeguarding their own health as well as the health of others [13].

Based on biological principles of disease transmission, safe(r) sex refers to sexual activities that avoid or reduce exchange of body fluids (semen, blood, vaginal fluids), avoid genital-to-genital contact and reduce risk of STI and HIV transmission, including reinfection. The most effective forms of safe(r) sex are: Non-penetrative sex (no penetration of the vagina, anus or mouth by the penis) including masturbation, mutual masturbation, kissing, sex-talking, massage and other forms of touching and stimulation, mutual monogamy or polygamy between partners with no pre-existing infection [14]. However protection depends on each partner being faithful and condom use with male or female condoms, including for vaginal and anal sex and non-lubricated male condoms for oral sex [14].

Among adolescents living with HIV, the importance of safer sex with an HIV negative sexual partner or one with uncertain status (an HIV sero-discordant relationship) is for self-protection from STIs and to protect the partner from becoming HIV infected. Between two people with HIV (an HIV sero-concordant relationship), the aim is to protect each other from STIs and re-infection. In an HIV discordant relationship, making sure the HIV negative partner or partners, whether regular or casual, remain negative is particularly challenging [14].

The genesis of the risky behaviours of positive adolescents can be attributed to depression and other pressures of living with the virus. Depressed adolescents living with HIV may be more apathetic and less concerned that they may be exposing themselves to additional infectious agents or risking infecting a partner with HIV, on the other hand, depressed adolescents living with HIV may seek to engage in unprotected sex to alleviate their depression more so, abuse of drugs may compromise their judgment in sexual relations and also hamper the effectiveness of ART [16].

The risk of sexual transmission of HIV increases if the partner living with HIV has a high viral load, e.g. during sero-conversion in the early stages of HIV infection and during late-stage disease. Between these stages the risk of infection is still present, but can be considerably lower. Concurrent STIs facilitate HIV transmission through genital ulcers, inflammation of vaginal and anal tissue and under the foreskin of the penis, and concentration of HIV in STI-related discharge and secretions. Women who have unprotected vaginal sex and both men and women who have unprotected anal penetration are more vulnerable biologically than men who penetrate their partners[14].

Developing relationships: Teenagers in early adolescence begin to have more interest in peers as romantic or sexual partners. Young adolescents often have intense feelings of love. Although they are likely to move in and out of relationships they can experience pain or unhappiness as a consequence of these experiences. The term "tender love" is sometimes used to describe the kind of love that adolescents experience since it involves feelings of tenderness and devotion, but infatuation is also common and can be equally distressing. Infatuation is different from "tender love" or "love" because it starts quickly but is not long lasting. When adolescents are infatuated they will tend to spend much time thinking about the person they are infatuated with [13].

Adolescents are faced with a challenge in developing relationships. Whether with friends or family, relationships are fraught with difficulty for young people living with HIV. UNICEF recently organized a dialogue with adolescents living with HIV in Zimbabwe. These wonderful, bright voices brought painful and piercing messages. Conscious of their HIV status, adolescents fear they may never experience a sustainable romantic relationship. If they are blessed with a loving and understanding partner, will the partner's family accept them? If so, how do they go about conceiving a child? In such resource poor countries, what are the risks and options? [17].

Age at first sexual debut: Uganda AIDS Indicator Survey 2011 asserts that thirteen percent of women and 12\% of men age 15- 24 had sexual intercourse before age 15. Youth with higher levels of education are less likely to begin sexual intercourse before age 15 . Among youth age $18-24,60 \%$ of women and $47 \%$ of men had sex before age 18 . Ever-married young women are markedly more likely to begin sexual intercourse before age 18 than never-married young women ( $70 \%$ versus $39 \%$ ). The difference by marital status among young men is less dramatic; $52 \%$ of ever-married young men age 18-24 had sex before age 18, compared to $45 \%$ of never married young men age 18-24 [5].

Myths about getting pregnant tell us that many girls have had little sex or contraceptive education. Research reveals that many teenagers believe that it is not possible to get pregnant at first sex, if a person doesn't have sex often, or if she is menstruating. For some teens the possibility of an unwanted pregnancy is of greater concern that reinfection with HIV or transmission of the virus [13].

\section{Significance of the study}

The study contributes knowledge in the area of HIV prevention programs among adolescents especially safe sex practices and including those who are already living with HIV. 
This study addresses issues of disclosure of HIV status by adolescents living with HIV to their partners and how they can be mitigated which can help in formulation of policies to be used in HIV prevention.

This study will be able to identify gaps in sexual practices of adolescents living with HIV which have not yet been addressed in sexual and reproductive health programs.

It will also benefit the country as it will bring out new findings on sexual practices of adolescents living with HIV as they can be looked at as vulnerable group of adolescents and also form a basis for further research.

\section{Rationale for the study}

All adolescents despite differences in their HIV status have a right to enjoy their sexuality since they have the same concerns. They have to be aware of the possible consequences of a sexual relationship and understand that having sexual feelings doesn't mean that sexual intercourse follows as they can express their feelings by talking to each other, holding hands, kissing, cuddling or touching [16]. These adolescents need appropriate sex education and support in addressing their sexuality/ sexual health since HIV treatment and care have reduced stigma and increased uptake of HIV testing and disclosure of positive status to their partners yet high adherence to antiretroviral therapy and safer sexual behaviour must go hand-in-hand [17].

Adolescents on ART are healthy, want to explore relationships just like their negative peers which calls for promotion of safer sex done in a sex-positive way where emphasis on sex as pleasurable, condoms and lubricants as erotic and non-penetrative sex as exciting should be used more often to encourage safer sex [14]. Due to the fact that individuals living with HIV who have unprotected sex could transmit HIV to their partners, they are also at a danger of re-infection with a different strain of the virus which causes a the disease to progress or get worse more quickly and contribute to the development of drug resistant forms of the virus, they become pregnant and contract STIs and get an increase in Viral load [13].

Health care workers, counsellors and educators need training and possibly sexuality education themselves in order to address sexual issues of adolescents living with HIV professionally, in a sex-positive way and without judgment. Discussing sex is taboo in many cultures, making the delivery of education to health workers and the discussion of safer sex by them with people living with and at risk of HIV very difficult [14].

\section{Materials and methods}

\section{Research Design}

This study utilised a cross sectional design with an analytical component comprising of both quantitative and qualitative approaches for data collection. The mixed method approach enabled the researcher to collect information that provided an indepth representation of the sexual practices of HIV positive adolescents. Participants for the study were selected from adolescents living with HIV undergoing HIV treatment and care services at Gombe hospital, Luwero health sub-district hospital, Kasawo health centre III, and Nsambya hospital homecare and from their service providers/counsellors.

\section{Research setting, Study Population and participants}

The study was conducted at Gombe hospital in Butambala district, Luwero health sub-district hospital in Luwero district, Nsambya hospital homecare in Kampala and Kasawo health centre III in Mukono district.

Quantitative data was collected from adolescents living with HIV aged 14-19 years attending HIV care services since in Uganda, $12 \%$ of females and $18 \%$ of males aged $15-19$ years have had sex by age $15,57 \%$ of females and $53 \%$ of males aged $18-19$ years have had sex by age 18..It included those who acquired HIV perinatally and those that got infected at a later stage of life from various causes [18].

Qualitative data was collected from their service providers/counsellors since it was difficult to conduct focus group discussions among the adolescents due to the sensitivity of the study (sexual practices) as its discussion is culturally considered a taboo.

\section{Inclusion criteria}

Registered, confirmed adolescents living with HIV were selected from the list of active patients of the Health facility. Eligible adolescents were active clinic patients under HIV care and treatment, either on ARVs or Cotrimoxazole prophylaxis or both and aware of their HIV positive status. They were aged 14-19 years. Service providers/ counsellors of these adolescents were also included in the study.

\section{Exclusion criteria}

Those who are registered confirmed adolescents living with HIV but not active patients at the health facility were excluded from the study. 


\section{Sampling strategy and Sample size selection}

Sample size determination: The sample size was calculated using the formula adapted by Getu. D and Tegbar. Y, (2006) as indicated below [19].

$$
n=\frac{Z^{2} P(1-P)}{w^{2}}
$$

Where; $Z$ is the value from statistical Tables, which contain the area under the normal curve, at 95\% confidence level is 1.96. $p$ is the estimated prevalence of outcome $=0.33$ $w$ is the desired level of precision (or acceptable error), taken at $5 \%$

$33 \%$ of adolescents living with HIV reported having had sexual intercourse7. This was used an estimated thirty three percent (33\%) prevalence (p) of outcome in calculating the sample size. At the $\mathrm{Z}$ value of $95 \%$ confidence level and with a $5 \%$ error term, the total survey sample size was got. This gave a sample size of 339 respondents with non-response leaving me with a total of 330 respondents.

$$
n=\frac{1.96^{2} \times 0.33(1-0.33)}{0.05^{2}}
$$

\section{Sample selection}

The researcher identified Kampala district as the urban district since it is the only city in the central region of Uganda and randomly selected a district in the north, east and west of Kampala as in the south it is lake Victoria. After writing districts in each direction on each on a single piece of paper, he placed those pieces of paper in a single direction in a tin and picked out one piece of paper (district) for each direction. Here he got Luwero in the north, Mukono in the east and Butamabala in the west. Wakiso district was not considered since it is peri-urban and borders Kampala in almost all directions.

In these districts, the researcher used purposive sampling of health units/ hospitals providing HIV care to adolescents aiming to have rural and urban health units. Purposive sampling was used at that stage because of the high level of bureaucracy involved to get permission to carry out studies in most of the high volume HIV/AIDS care facilities especially those under Non-governmental organisations and other Private not for profit facilities which levied a high fee for permission to be granted.

After all this hustle, four (4) health units were identified which included;

1. Gombe Hospital (Butambala district)

2. Kasawo Health Centre III (Mukono district)

3. Luwero Health sub-district hospital (Luwero district)

4. Nsambya Hospital homecare department (Kampala district)

After identifying the four health units, the researcher used random sampling to select adolescents living with HIV aged 14-19 years to participate in the study and the sampling frame consisted of adolescents living with HIV in the records of the health unit who were still active clients. In most health units, every $2^{\text {nd }}$ adolescents living with HIV coming for care was requested to participate in the study and whoever consented was interviewed until the required sample size was reached. The representation was, Gombe Hospital 106 respondents, Kasawo Health Centre III 89 respondents, Luwero Health sub-district hospital 75 respondents and Nsambya Hospital homecare department 60 respondents.

For qualitative data, the researcher used purposive sampling and got 4 key informants (1 per Health unit).

Data collection: Data was collected from February to July 2013. The researcher collected primary data from adolescents living with HIV from April to August 2013. The study made use of multiple data collection methods which included interview schedules and key informant interviews. Focus group discussions were not included due to the sensitivity of the study.

\section{Qualitative data}

Key informant interviews: The researcher collected information using a key informant guide from key service providers/ counsellors who provide HIV care in the health facility on a day to day basis. Here data on knowledge about HIV status, issues with developing relationships and sexual debut, past sexual encounters and disclosure to partner and pregnancies was collected. This provided an in depth understanding of their sexual practices.

Quantitative data: The researcher collected primary data from adolescents living with HIV by interviewing them using an interview schedule since the information being collected was considered high sensitive by culture hence the need for the researcher to respect the social cultural aspect. Also the adolescents required clearer explanations, understanding and interpretation of the 
questions which could all be achieved in using interview schedules. Here data about Demographic characteristics, knowledge about HIV status, issues with developing relationships and sexual debut, past sexual encounters and disclosure to partner and safer sexual practices was collected.

Interview schedule for study participants: Data was collected using a semi- structured interview guide. Open ended questions were also used to elicit information from the respondents. The interview guide was used as this was administered by the interviewer to the Adolescents at the onset of each interview session; the purpose of the study was clearly explained to the study participants. The study participants were informed that their participation in the study was voluntary, they had the right to withdraw from the study at any time and the information given was confidential and only for the purpose of the study as their names or clinic numbers were not be required.

The Interview schedule was used to collect socio-demographic characteristics of the study participants, ages at first sexual debut, issues to do with disclosure to their partners, safer sexual practices and factors associated with sexual activity among them.

\section{Validity and reliability of the tools}

Self-checking questions were paused using the Interview schedules and questions with options from which to choose from were included in the data collection tools to ensure that the relevant information was collected.

\section{Data Management and Quality control}

The researcher pre-tested the data collection tools from Nakaseke hospital to see if there were any modifications needed before the actual data collection process. During data collection, the researcher ensured completeness of information collection. Data collection tools were reviewed during the field visits and errors and discrepancies addressed while still in the field. All interview tools were coded before data entry. Completed interview schedules were bundled for data capture and analysis and subsequently filed for future reference. Captured data was backed up by the researcher.

Coding and Data Editing: As a measure of reducing data, coding was done. The researcher identified the themes and refined them to the point where they can be applied to an entire text. This forced the researcher to make judgments about the meanings of contiguous blocks of text.

Qualitative data: Field notes were elaborated into comprehensible phrases or sentences as soon as the researcher left the field or the informant.

Quantitative data: After each session, each interview schedule was checked for completeness and thereafter data coded. The editing of data followed the process of grouping the answers into categories and numbering them which served a purpose of detecting and eliminating errors in the completed interview schedules before coding. Coding was undertaken after editing in an attempt to reduce data from detailed to summarized and understandable data. In coding the responses to open-ended questions, categories were made according to similarity of answers and judgment of the researcher. The numbers of responses to each category were then recorded. For questions having more than one response, the researcher constructed a coding frame for each question and counted the number of responses to each alternative category. The researcher then made an effort to show how the data obtained from the respondents was processed and analysed and thereafter organised in a proper and meaningful pattern.

\section{Data Processing and Analysis}

Data processing and analysis was carried out with the aim of reducing raw data into manageable proportions and summarising it in a form that brought out salient features. The key questions of the study were investigated both qualitatively and quantitatively and thus the results are presented statistically and thematically.

Qualitative Data: Qualitative data enabled the researcher to gain insights into individual's thoughts, behaviour and emotions concerning sexual practices of HIV positive adolescents. The use of multiple methods of data collection facilitated triangulation and offered an opportunity to critique emerging meanings. It also made it possible to generate coherent arguments and narratives.

The first phase of analysis included making decisions on the content and information gathered during Key informant interviews, identifying appropriate and sufficient manner for interpreting and conveying the information. Hand-written notes from Key informant interviews were typed into a word processing programme, Microsoft Word, taking special consideration of the words of participants, the context of the words, internal consistency, and frequency of comments, the extensiveness of comments and the specificity of comments. The notes were read thoroughly and classified into meaningful categories so as to bring out their essential patterns and main themes of the study. The qualitative data analysis process focused on interpretation and analysis of texts to discover meaningful patterns (Thematic analysis).

Quantitative Data: Quantitative data was cleaned and open ended responses coded. Data was captured and entered into epidata 3 in preparations for analysis, and analysed using STATA 12. Data collected from the field was validated and coded before being analysed. Analysis followed standard statistical guidelines starting with descriptive statistics followed by inferential statistics. Descriptive statistics examined the distribution of each study variable and were also used to summarize the demographic data of the study sample, which were presented in form of frequency tables, and expressed as frequencies and percentages. Frequencies 
and proportions were used to examine the distribution of categorical variables while means and standard deviations were used for continuous variables. Further statistical and descriptive analysis, cross-tabulations between the independent and dependent variables to establish meaningful relationships between variables were also carried out. $\mathrm{Chi}^{2}$ and student t- test were used to predict significant statistical relationships between variables with a p-value less than 0.05 . The likelihood of occurrence of outcomes was assessed for using relative risk (RR) and odds ratios (OR). Frequency tables, descriptive statistics, graphs and charts were used in the presentation of the findings.

\section{Ethical considerations}

Prior to commencement of the study, the researcher sought approval from the Health facility administration. The researcher also ensured the respondents' privacy and anonymity by not including the study participants' names on the interview schedules. Furthermore, the study participants were safeguarded against physical, emotional, psychological and /or sociological aspects that could hinder carrying out a successful study and other barriers that could harm or constitute a violation of human rights by seeking for verbal consent from the study participants.

Informed Consent: Study participants were informed that participation in the study is voluntary and should not therefore expect other benefits for participating in the study. They were also informed that the study would contribute to the overall service delivery, programming and planning. Respondents were directly consulted before commencing the interview, objectives explained to them and verbal consent obtained, and when they consent to being interviewed, they were interviewed. For those below 18 years a verbal consent was sought from their caretakers. All study related information was collected on a voluntary basis and no remuneration or inducement was given to the study participants. The respondents have a right to read through the final report, which is accessible to the general public through the researcher, Kyambogo University Library and as a publication. Anonymity was observed as information given by the study respondents was not referencing their names without their consent. Hence data to be collected for purposes of this study did not contain identifying information of the study participants.

\section{Results}

\section{Overview}

The previous chapter described the research methods used for the study. In this chapter, quantitative and qualitative study findings of the sexual practices of adolescents living with HIV are presented. This chapter also presents four major themes that emerged during the analysis of quantitative and qualitative data, namely:

1. Determinining whether adolescents living with HIV disclose their HIV status to their sexual partners.

2. Identification of factors associated with sexual activity among adolescents living with HIV.

3. Finding out if these adolescents practice safe sex.

4. Determine age at first sexual debut among adolescents living with HIV.

\section{Socio-demographic characteristics of the study respondents}

The participants' background information comprised of the socio and demographic information of adolescents living with HIV and the people that they stay with.

Age of the respondents: Descriptive data findings indicate that most Adolescents 30\% (99/330) were aged 19years, followed by those aged 14 years $20.3 \%$ (67/330). Those of age 18 were $15.2 \%(50 / 330)$, 17 years $13.6 \%(45 / 330), 15$ years (42/330) and the least were 16years making $8.2 \%(27 / 330)$.

Sex of the respondent: Findings from the study show that majority of the respondents were females $64.4 \%(213 / 330)$ and males were $35.6 \%$ (117/330). Further analysis shows that among the females, (40) were of age 14, (27) of age 15, (20) of age 16, (31) of age $17,(35)$ of age 18 and (76) of age 19 out of a total of 229 female while for the male, (34) were of age 14, (19) of age 15, (11) of age $16,(18)$ of age $17,(19)$ of age 18 and (31) of age 19 out of a total of 133 males $(\mathrm{P}=0.230)$.

Marital status of the respondents: Data findings show that majority of the respondents were single $72.7 \%(240 / 330)$. However there were also married adolescents living with HIV accounting for 21.8\% (72/330) of the respondents, 3.6\% (12/330) had separated from their spouses, another 1.5\% (5/330) were widowed while $0.3 \%(1 / 330)$ belonged to the other. There was only (1) married 14 year old, more to this most of the married were aged 19years (41), followed by those of 18 years (23), and those aged 17years (13). Further analysis shows that among the females, (144) were single as compared to the (61) who were married, the (7) divorced and the (15) who had separated. Among the males, (110) were single, another (21) married and (2) divorcees ( $\mathrm{P}=0.002)$.

Educational status: Analysis here shows that 50.3\% (166/330) of the respondents were not in school while 49.7 (164/330) were in school. Of those in school, $46.3 \%(76 / 164)$ were males and $53.7 \%(88 / 164)$ were females $(\mathrm{P}=0.000)$. More to this, the highest number of those in school was among the 14year olds (65) and least among the 18year olds (12). Yet for those not in schools, the 19 year olds accounted for the highest number (86) and the lowest was for the 10 year olds (10). Among the respondents, $0.6 \%$ $(2 / 325)$ had at least attained adult literacy, 10.5\% (34/325) Lower primary, 32.3\% (105/325) Upper primary, 34.8\% (113/325) OLevel, 10.2\% (33/325) A-level, 3.1\% (10/325) University/Tertiary, 8.3\% (27/325) Non-formal education and the remaining $0.3 \%$ $(1 / 325)$ had attained other forms of education (Table 1$)$. 


\begin{tabular}{|c|c|}
\hline Background characteristics & Number (\%) \\
\hline Age & $N=330$ \\
\hline 14 & $67(20.3)$ \\
\hline 15 & $42(12.7)$ \\
\hline 16 & $27(8.2)$ \\
\hline 17 & 45 (13.6) \\
\hline 18 & $50(15.2)$ \\
\hline 19 & $99(30.0)$ \\
\hline Median age 17 years & $\mathrm{IQR}=2$ \\
\hline Sex & $N=330$ \\
\hline Male & $117(35.5)$ \\
\hline Female & $213(64.5)$ \\
\hline Religion & $N=330$ \\
\hline Catholic & $109(33.0)$ \\
\hline Protestant & $71(21.5)$ \\
\hline SDA & $10(3.0)$ \\
\hline Pentecostal & $47(14.2)$ \\
\hline Other Christian & $13(3.9)$ \\
\hline Muslim & $80(24.2)$ \\
\hline Marital status & $N=330$ \\
\hline Single & $240(72.7)$ \\
\hline Married & $72(21.8)$ \\
\hline Widowed & $5(1.5)$ \\
\hline Separated & $12(3.6)$ \\
\hline Others & $1(0.3)$ \\
\hline Education level attained & $N=325$ \\
\hline Adult literacy & $2(0.6)$ \\
\hline Lower primary & $34(10.5)$ \\
\hline Upper primary & $105(32.3)$ \\
\hline O- level & $113(34.8)$ \\
\hline A- level & $33(10.2)$ \\
\hline University/tertiary & $10(3.1)$ \\
\hline Non formal education & $27(8.3)$ \\
\hline Other & $1(0.3)$ \\
\hline Employment & $N=97$ \\
\hline Business & $37(38.1)$ \\
\hline Farming & $28(28.9)$ \\
\hline Petty trade & $25(25.8)$ \\
\hline Education & $2(2.1)$ \\
\hline Housemaid & $5(5.2)$ \\
\hline People they stay with & $N=324$ \\
\hline Mother & $47(14.5)$ \\
\hline Father & $30(9.3)$ \\
\hline Both parents & $41(12.7)$ \\
\hline Partner & $68(21.0)$ \\
\hline Grand parents & $39(12.0)$ \\
\hline Aunt/uncle & $36(11.1)$ \\
\hline Brother/sister & $30(9.3)$ \\
\hline Other & $19(5.9)$ \\
\hline Alone & $14(4.3)$ \\
\hline
\end{tabular}

Table 1: Socio-demographics of the study respondents 
Religious affiliation: Findings from the study show that $33.0 \%(109 / 330)$ of the respondents were Catholics, 24.2\% (80/330) were Muslim, 21.5\% (71/330) Protestant, 14.2\% (47/330) Pentecostal, 3.9\% (13/330) Other Christian and 3.0\% (10/330) SDA.

Employment status: Findings from the study show that 29.5\% (97/329) of the respondents were employed with $0.6 \%(2 / 329)$ of those still in school. More to that, among the employed, 38.1\% (37/97) were in Business, 28.9\% (28/97) in Farming, 25.8\% (25/97) in Petty trading, 2.1\% (2/97) in Education and 5.2\% (5/97) work as House maids.

With whom they live: Analysis shows that 14.5\% (47/324) live with their mothers, 9.3\% (30/324) live with their fathers, $12.7 \%$ (41/324) live with both parents, 21.0\% (68/324) live with their partners, $12.0 \%$ (39/324) with their grandparents, $11.1 \%(36 / 324)$ with their Aunties/ Uncles, 9.3\% (30/324) with their brother/sister, 5.9\% (19/324) with another category of people and 4.3\% (14/324) live alone. Furthermore 17.5\% (56/320) of the respondents had their mothers alive, 18.4\% (59/320) had their fathers alive, $29.4 \%(94 / 320)$ had both parents alive and $34.7 \%(111 / 320)$ had neither of the parents alive.

\section{Determining whether adolescents living with HIV ddisclose their HIV status to their sexual partners}

Awareness of their HIV positive status: In this study, 97.9\% (323/330) of the respondents were aware of their HIV positive status while $2.1 \%$ (7/330) were not. For those who were aware, Majority of them $41.3 \%(132 / 320)$ got to know of their HIV status when they were in the age bracket of 11-14years followed by $40.0 \%(128 / 320)$ of 15 -19years and then lastly $18.8 \%$ (60/320) found out about their HIV status when still below 10years. Of these, 67.5\% (216/320) were disclosed to by healthworkers, followed by their mothers $15.0 \%$ (48/320), socialworkers 7.2\% (23/320), Fathers 3.7\% (12/320), aunt/uncle 3.1\% (10/320), grandparents $1.9 \%$ $(6 / 320)$, brother/sister $1.6 \%(5 / 320)$ and others $0.3 \%(1 / 320)$.

On further analysis, adolescents living with HIV aged 17 or more had a $0.4 \%$ likelihood of knowing their HIV status than those aged less than 17 years (RR 1.040[95\% CI 1.003-1.081]; Chi ${ }^{2}$ value - 5.8460; p-value $=0.0156$ ), males were $49 \%$ more likely to know their HIV status earlier when they are 14years or younger than females (RR 1.49[95\% CI 1.26-1.76]; Chi ${ }^{2}$ value - 18.8813; p- value $=0.0000$ ), those living with parents were $53 \%$ more likely to know their HIV status when they are 14 years or younger than those not living with their parents (RR 1.53[95\% CI 1.29-1.82]; Chi2 value - 22.173; p- value $=0.0000$ ). and those disclosed to by a parent or relative were $69 \%$ more likely to know their HIV status when they are 14 years or younger (RR 1.69[95\% CI 1.45-1.97]; Chi2 value -30.85 ; $\mathrm{p}$ - value $=0.0000$ ). This is illustrated in the (Table 2 ) below;

\begin{tabular}{|c|c|c|c|c|}
\hline Age & Know their HIV status & $\begin{array}{l}\text { Don't know } \\
\text { their HIV status }\end{array}$ & $\begin{array}{c}\text { Relative } \\
\text { Risk }\end{array}$ & P-value \\
\hline$>/=17$ years & 193 & 01 & $\begin{array}{c}194 \\
\text { RR } 1.04\end{array}$ & 0.0156 \\
\hline \multirow[t]{2}{*}{$<17$ years } & 130 & 06 & 136 & \\
\hline & 323 & 7 & 330 & \\
\hline Age of knowing HIV status & $</=14$ years & $>14$ years & & \\
\hline Male & 86 & 27 & $\begin{array}{c}113 \\
\operatorname{RR} 1.49\end{array}$ & 0.0000 \\
\hline \multirow[t]{2}{*}{ Female } & 106 & 101 & 207 & \\
\hline & 192 & 128 & 320 & \\
\hline Age of knowing HIV status & $</=14$ years & $>14$ years & & \\
\hline Living with a parent & 90 & 25 & $\begin{array}{c}115 \\
\text { RR } 1.53\end{array}$ & 0.0000 \\
\hline \multirow[t]{2}{*}{ Not living with a parent } & 95 & 91 & 186 & \\
\hline & 185 & 116 & 301 & \\
\hline Age of knowing HIV status & $</=14$ years & $>14$ years & RR 1.69 & 0.0000 \\
\hline $\begin{array}{c}\text { Disclosed to by parent/ } \\
\text { relative }\end{array}$ & 69 & 11 & 80 & \\
\hline \multirow[t]{2}{*}{$\begin{array}{l}\text { Disclosed to by Health/ } \\
\text { social worker }\end{array}$} & 121 & 116 & 237 & \\
\hline & 190 & 127 & 317 & \\
\hline
\end{tabular}

Table 2: Cross-tabulations on disclosure of HIV status to the adolescents

Respondents in sexual relationships: Analysis of data from this study reveals that, $35.2 \%(116 / 320)$ of the respondents were in an active sexual relationships while $64.8 \%$ (214/330) were not. Of those $75 \%(87 / 116)$ were females as compared to $25 \%$ (29/116) being males. $(\mathrm{P}=0.003)$. For those in an active relationship, $66.7 \%(72 / 108)$ had disclosed their HIV status to their partners while the remaining $33.3 \%(36 / 108)$ had not were $75 \%(54 / 72)$ were females and $25 \%(18 / 72)$ males $(\mathrm{P}=0.75)$. 
Majority of those who had disclosed gave the reason of loving their spouses $25.7 \%$ (9/35), followed by those who did so to prevent re-infection or infecting their spouses $20 \%(7 / 35), 17.1 \%(6 / 35)$ for their spouses to know what is happening, $14.3 \%(5 / 35)$ to get help, 8.6\% (3/35) for their freedom, 5.7\% (2/35) due to the fact that their spouses had infected them, 2.9\% (1/35) because the spouse wanted to know, 5.7\% (2/35) the spouse didn't want to disclose. For those who had disclosed, 84.3\% (43/51) were of the same HIV status as their partners as opposed to $15.7 \%(8 / 51)$ who were not (p- value $=0.002$ ). Majority of those who had not disclosed to their partners 36\% (9/25) felt guilty, 16\% (4/25) feared to be chucked by their spouses, $16 \%(4 / 25)$ never minded about disclosing to their spouses, $12 \%(3 / 25)$ had no answer, $12 \%(3 / 25)$ knew it was dangerous but had nothing to do, $4 \%(1 / 25)$ feared conflict and $4 \%(1 / 25)$ feared stigma that would result from disclosure.

On further analysis, there was no association between sex of the respondent and disclosure (p-value $=0.75$ ), adolescent males living with HIV were 39\% more likely to have sexual partners of the same HIV status than their female counterparts (RR 1.39[95\% CI 1.16-1.67]; p- value $=0.02$ ).

Key informants also brought up issues related to disclosure which included:

"Many of them fear their status to be known to others as they have stigma about their HIV status and this leads them to keep their secret" (KI A).

"They fear to be discriminated once their status is known as rumours can move around" (KI D).

"Many of those who come to our centre are not from nearby villages because they have stigma about their HIV status and it becomes difficult for them to disclose it to their partners" (KI C)

\section{Identification of factors associated with sexual activity among adolescents living with HIV}

Ever been in a sexual relationship: In this study $47.7 \%(157 / 329)$ of these adolescents living with HIV had ever been in a sexual relationship as compared to $52.3 \%(172 / 329)$ who had never.

Females were 51\% more likely to have ever been in a sexual relationship than males (RR 1.51[95\% CI 1.15-1.98]; Chi2 value 10.173; p- value $=0.0014$ ), Those from Nsambya homecare had a 59\% likelihood of having never been in a sexual relationship than those from Kasawo Health centre III, Luwero Health centre IV and Gombe Hospital (OR 0.59[95\% CI 0.39-0.88]; Chi2 value - 8.686; p- value $=0.0032$ ), females were $65 \%$ more likely to be sexually active than the males (RR 1.65[95\% CI 1.16-2.35]; Chi2 value -8.54 ; $\mathrm{p}$ - value $=0.0035)$ and those older than 17 years are 3.6 times more likely to be sexually active than those 17 years and younger (RR 3.64[95\% CI 2.5-5.2]; $\mathrm{Chi}^{2}$ value - 64.35; p- value $=0.0000$ ) as illustrated in the (Table 3 ) below.

\begin{tabular}{|c|c|c|}
\hline & Ever been in a sexual relationship & $\begin{array}{c}\text { Never been in a } \\
\text { Sexual relationship }\end{array}$ \\
\hline Female & 115 & 97 \\
\hline Male & 42 & 75 \\
\hline & 157 & 172 \\
\hline Nsambya Home care & Ever been in \\
\hline Kasawo H/C, & 18 & 41 \\
\hline Gombe Hosper been in a \\
\hline
\end{tabular}

Table 3: Cross tabulations on sexual relationships

Most of the adolescents seek emotional care from counsellors 30.7\% (81/264) followed by from parents 28.4\% (75/264), from peers 27.3\% (72/264), HIV positive group 19.7\% (52/264), relatives 5.3\% (14/264) and religious leaders 5.3\% (14/264). However, those seeking emotional care from a hospital setting (Counsellors and HIV positive group) were 1.7 times more likely to be sexually active than those seeking emotional care from other sources (Parents, relatives, peers and religious leaders) (RR 1.74[95\% CI 1.282.38]; p- value $=0.0004$ ). 
Views from key informants included;

"Many of them have ever had sex and they don't tell us because they think that we will abuse them and many of them who have it say that they also want to feel like other adolescents" (KI B).

"We have many who say that they have never had sex and this could be due to the fact that they spend most of their time in school" (KI A).

Factors that prompted them to have sex at that time: Majority $54.6 \%(83 / 152)$ of them were compeled into sexual activity because of peer pressure, $28.9 \%$ (44/152) due to economic presure, $8.6 \%$ (13/152) due to rape/coercion/ forced into marriage, $4 \%$ $(6 / 152)$ wanted to discover and $4 \%(6 / 152)$ said that they were old enough/ due to demands of nature. More to that, More females $32.9 \%(50 / 152)$ reported that it was due to peer pressure than males $21.7 \%(33 / 152)$ (p-value $=0.000)$.

\section{Finding out if these Adolescents Practice Safe Sex}

Sexual practices engaged in: In this study, of the 47.7\% (157/329) who had ever had sexual activity, 85.3\% (134/157), had actual sexual intercourse and were also engaged in hugging, fondling, kissing and fantasising about love representing 40\% (134/130) of all the respondents. $0.64 \%(2 / 157)$ had only hugged their partners while another $0.64 \%(2 / 157)$ had only been invoved in fondling and $15.3 \%(21 / 157)$ partipated in masturbation. However there was no association between sexual practice and sex ( $\mathrm{p}$-value $=$ $0.48)$.

Condom use: Among those who had sexual intercourse, 41.9\% (65/155) used condoms while 58.1\% (90/155) did not were, 24.5\% $(38 / 155)$ were males as compared to $75.5 \%(117 / 155)$ females ( $\mathrm{p}$-value $=0.660)$. For those who did not use condoms, majority of them $41.2 \%$ (35/85) thought that their partner was safe, $24.7 \%(21 / 85)$ felt it was not necessary to use condoms, $14.1 \%(12 / 85)$ lacked awareness about condom use, $8.2 \%$ (7/85) wanted to have a baby, 4.7\% (4/85) of the respondents wre either raped or defiled, $3.5 \%(3 / 85)$ had partners who did not want to use condoms and the remaining $3.5 \%(3 / 85)$ did not have money to buy condoms.

Findings further reveal that majority of those adolescents who have ever had sexual activity 43.2\% (54/125) sometimes use condoms, $30.4 \%$ (38/125) do not use condoms at all, 14.4\% (18/125) use condoms most of the time, 12\% (15/125) use them always.

Still related to condom use, majority of those who use condoms, $29.7 \%$ (27/91) want to prevent pregnancy, 26.4\% (24/91) to prevent infecting partner with HIV/STIs, prevent HIV infection, prevent HIV re-infection and prevent pregnancy. 14.3\% (13/91) wanted to prevent HIV re-infection and prevent pregnancy $11 \%$ (10/91) wanted to prevent infecting partner with HIV/STIs and prevent HIV infection. 7.7\% (7/91) wanted to prevent HIV re-infection only, 5.5\% (5/91) wanted to prevent HIV infection only, $3.3 \%(3 / 91)$ to prevent infecting partner with HIV/STIs and prevent pregnancy, $2.2 \%(2 / 91)$ wanted to prevent infecting partner with HIV/STIs and prevent HIV re-infection.

Key Informants had this to say;

"Some of them ask for condoms especially the older male adolescents but it's rare for the females to ask for condoms you just see them come to you pregnant and wanting to abort or with Sexually Transmitted Infections" (KI D).

"Some of them become sexually active as a result of being forced into marriage and a few of them also get HIV from these forced early marriages since early marriages are rampant in our catchment area" (KI D).

Reasons for not having engaged in sexual activity: In this study, 48.5\% (80/165) of the respondents had not yet engaged in sexual activity because they felt that they are still young, $27.3 \%$ (45/165) wanted to finish their studies, 9.1\% (15/165) just didn't want to engage in sexual activity, $7.9 \%$ (13/165) didn't want to spread HIV to others, $2.4 \%(3 / 165)$ wanted to finish their studies and didn't want to spread HIV to others, $1.8 \%$ (3/165) said that it was normal, 1.2\% (2/165) had never tested sex, another $1.2(2 / 165)$ feared people to know their status and the remaining $0.6 \%$ (1/165) said that everyone in the village knew status which makes it hard for them to engage in sexual activity.

Other methods used to prevent re- infection: Among those who were sexually active, majority of them 28.9\% (35/121) used being faithful to their spouse as a measure to prevent re-infection with HIV, 19.8\% (24/121) were abstaining, 17.4\% (21/121) were faithful to their partners and not sharing skin piercing instruments, $13.2 \%(16 / 121)$ were not sharing skin-piercing instruments, $8.3 \%(10 / 121)$ were abstaining and not using skin piercing instruments, $6.6 \%(8 / 121)$ thought contraceptives would prevent reinfection, $5.0 \%$ (6/121) were not using any method, and $0.8 \%(1 / 121)$ were using other methods.

Partners currently steady with: Findings from this study show that, among those who had sexual partners, 87.2\% (75/86) had one partner, 8.1\% (7/86) had two partners, 3.5\% (3/86) had three partners and 1.2\% (1/86) had four partners.

\section{Determining age at first sexual debut among adolescents living with HIV}

For those who have ever had sex, majority of them $29.0 \%$ (45/155) had it at between $17-18$ years, followed by $27.1 \%(42 / 155)$ at $15-16$ years, then $24.5 \%(38 / 155)$ at $13-14$ years, then $10.3 \%(16 / 155)$ at $18-19$ years and lastly $9.0 \%(14 / 155)$ at $11-12$ yrs. 
None of them had age at first sexual debut below 10 years. Ages of their partners also varied were majority $34.8 \%$ (54/155) were between $19-22$ years, followed by $27.7 \%$ (43/155) who were above 23 years, then $26.5 \%(41 / 155)$ between $15-18$ years, then $9.7 \%$ (15/155) between 11-14yrs and lastly $1.3 \%(2 / 155)$ below 10 years.

Further analysis reveals that in all age groups the majority of males $31.7 \%(13 / 41)$ had their sexual debut between $15-16 y e a r s$ and the minority $7.3 \%$ (3/41) between $11-12$ years as compared to majority of females $30.7 \%(35 / 114)$ who had theirs between $17-18$ years with the least $9.6 \%(11 / 114)$ at 18 -19years and another $9.6 \%(11 / 114)$ at $11-12$ years. However sexual debut at $11-12$ years, there were more females $7.1 \%(1 / 155)$ as compared to males $1.9 \%(3 / 155)$ ( $\mathrm{p}$-value $=0.87)$.

\section{Service centres}

In this study, adolescents living with HIV were seeking HIV care and services from different centres and majority of them $32.1 \%$ (106/330) from Gombe hospital, 27\% (89/330) from Kasawo healthcentre III, 22.7 (75/330)from Luwero healthcentre IV and $18.2 \%$ (60/330) from Nsambya hospital homecare.

\section{Discussion}

\section{Disclosure of HIV status}

In this study, $97.9 \%$ of the respondents were aware of their HIV positive status with many of them $41.3 \%$ being disclosed to when they were in the age bracket of 11 -14years followed by $40.0 \%$ of 15 -19years with majority $67.3 \%$ being disclosed to by healthworkers. This can be compared to a study in South Africa were only $68.1 \%$ of the adolescents living with HIV knew their status [20]. Males were 49\% more likely to know their HIV status earlier when they are 14years or younger than females (RR 1.49; p- value $=0.0000$ ), those living with parents were $53 \%$ more likely to know their HIV status when they are 14 years or younger than those not living with their parents (RR 1.53; p- value $=0.0000)$ and those disclosed to by a parent or relative were $69 \%$ more likely to know their HIV status when they are 14 years or younger than those disclosed to by health or social worker (RR 1.69; $\mathrm{p}$ - value $=0.0000)$.

$35.2 \%$ of the respondents were in an active sexual relationships with $75 \%$ of them being females $(\mathrm{P}=0.003)$. This can be compared to a study in Uganda which showed that $52 \%$ of adolescents living with HIV are in active sexual relationships [7]. For those in an active relationship, $66.7 \%$ had disclosed their HIV status to their partners with $25.7 \%$ of them giving a reason for disclosure as loving their spouses followed by $20 \%$ to prevent re-infection or infecting their partners and $36 \%$ of those who did not disclosed to their partners felt guilty about it. For those who had disclosed, $84.3 \%$ were of the same HIV status as their partners as opposed to $(15.7 \%)$ who were not ( $\mathrm{p}$-value $=0.002)$. This is in disagreemnet with another study in Uganda where only $31 \%$ had ever disclosed to their partners and another one in South Africa were $41.5 \%$ of those sexually active knew their partners status and $35 \%$ had disclosed to their partners $[19,21]$. On further analysis, there was no association between sex of the respondent and disclosure ( $\mathrm{p}$-value $=0.75)$, Males were $39 \%$ more likely to have sexual partners of the same HIV status than their female counterparts $(\mathrm{RR}$ 1.39 ; $\mathrm{p}$ - value $=0.02$ ).

\section{Factors associated with sexual activity among adolescents living with HIV}

Females were 51\% more likely to have ever been in a sexual relationship than males (RR 1.51; p- value =0.0014), adolescents living with HIV from urban areas were more likely not to be in a sexual relationship than those in rural areas as reflected by the finding of adolescents living with HIV from Nsambya homecare who by the fact of being from Nsambya homecare, had a $61 \%$ likelihood of protection from sexual relationships than those from Kasawo Health centre III, Luwero Health centre IV and Gombe Hospital (RR 0.59 ; $\mathrm{p}$ - value $=0.0032)$, females were $65 \%$ more likely to be sexually active than the males (RR 1.65 ; $\mathrm{p}$ - value $=0.0035)$ and those older than 17 years are 3.6 times more likely to be sexually active than those 17 years and younger (RR 3.64; $\mathrm{p}$ - value =0.0000). In another study done in Uganda, adolescents living with HIV aged 15-19 years were more likely to be sexually active compared to those aged 10-14 years (AOR 6.28) [22].

In this study $47.7 \%$ of these adolescents living with HIV had ever been in a sexual relationship with $53.3 \%$ of them being compeled into sexual activity because of peer pressure which is in agreement with a study done in Uganda which showed that $45 \%$ of them have ever had sex [21]. However in South Africa, only 14.9\% of adolescents living with HIV had ever had sex [19]. More to that, $44 \%$ of perinataly infected adolescents living with HIV reported a desire to have sexual intercourse [7].

Many of them $30.7 \%$ seek emotional care from counsellors followed by $28.4 \%$ from parents, however, those seeking emotional care from a hospital setting (Counsellors and HIV positive group) were 1.7 times more likely to be sexually active than those seeking emotional care from other sources (Parents, relatives, peers and religious leaders) (RR 1.74; p- value $=0.0004$ ) probably explained in another study done in Uganda were HIV positive adolescents are more likely to talk to service providers/counsellors about sexual issues than to their parents/relatives [7].

\section{Safer sex practices among adolescents living with HIV}

In this study, $40 \%$ of the respondents reported having had sexual intercoursewhich is an increase when compared to another 
study done in Uganda in 2008 were 33\% of adolescents living with HIV reported having had sexual intercourse [7]. However there was no association between sexual practice and sex $(\mathrm{p}$-value $=0.48)$.

Among those who had sexual intercourse, $41.9 \%$ used condoms. Among the sexually active adolesents, $43.2 \%$ sometimes use condoms with a majority of those who use condoms $29.7 \%$ wanting to prevent pregnancy followed by $26.4 \%$ to prevent infecting partner with HIV/STIs, prevent HIV infection, prevent HIV re-infection and prevent pregnancy. In a study done in Uganda, 57\% of adolescents living with HIV didn't consistently use condoms [21]. For those who did not use condoms, majority of them $41.2 \%$ thought that their partner was safe, $24.7 \%$ felt it was not necessary to use condoms.

Finding reveal that $48.5 \%$ of the respondents had not yet engaged in sexual activity because they felt that they are still young, $27.3 \%$ wanted to finish their studies and others gave various reasons which included, 9.1\% just didn't want to engage in sexual activity, $7.9 \%$ didn't want to spread HIV to others, $2.4 \%$ wanted to finish their studies and didn't want to spread HIV to others, $1.8 \%$ said that it was normal, $1.2 \%$ had never tested sex, another $1.2 \%$ feared people to know their status and the remaining $0.6 \%$ said that everyone in the village knew status which makes it hard for them to engage in sexual activity. In comparison, $41 \%$ of adolescents living with HIV feel that there is no reason why someone who is HIV positive should have sexual intercourse [7].

Among those who were sexually active, majority of them $28.9 \%$ used being faithful to their spouse as a measure to prevent re-infection with HIV, 19.8\% were abstaining, $17.4 \%$ were faithful to their partners and not sharing skin piercing instruments, $13.2 \%$ were not sharing skin-piercing instruments, $8.3 \%$ were abstaining and not using skin piercing instruments, $6.6 \%$ thought contraceptives would prevent re-infection, $5.0 \%$ were not using any method, and $0.8 \%$ were using other methods. In another study done in Uganda, $37 \%$ of them reported using a method to prevent re-infection [7].

Findings from this study show that, among those who had sexual partners, $87.2 \%$ had one partner, and $12.8 \%$ had more than two sexual partners. This is in disagreement with another study done in Uganda which shows that $30 \%$ of adolescents living with HIV have more than one sexual partner [21].

\section{Age at first sexual debut among adolescents living with HIV}

For those who have ever had sex, majority of them $29.0 \%$ had it at between $17-18$ years, followed by $27.1 \%$ at $15-16$ years, then $24.5 \%$ at $13-14$ years, then $10.3 \%$ at $18-19$ years and lastly $9.0 \%$ at $11-12 y r s$. None of them had age at first sexual debut below 10 years. Further analysis reveals that in all age groups the majority of males $31.7 \%$ had their sexual debut between $15-16 y e a r s$ and the minority $7.3 \%$ between $11-12$ years as compared to majority of females $30.7 \%$ who had theirs between $17-18$ years with the least $9.6 \%$ at 18 -19years and another $9.6 \%$ at $11-12$ years. In another study done in Uganda among adolescents living with HIV, the mean age of sexual debut was 15.8 years [22].

Reproductive health needs of adolescents living with HIV have to be addressed and emphasis put on adolescent counselling and formation of teens or adolescent clubs for adolescents living with HIV. Programs to address condom use and safer sexual practices in this group should be setup and promoted. Health facilities should stop charging exorbitant fees from researchers.

Further studies need to be undertaken in; comparing the reproductive health behaviours of adolescents living with HIV in rural and urban areas, assessing the effect of education on sexual practices of adolescents living with HIV.

It is one of the very few studies that have tried to assess the sexual and reproductive practices of adolescents living with HIV accessing HIV/AIDS care services in Uganda and therefore making a great contribution to the body of knowledge in the area of Adolescent Sexual and Reproductive Health among adolescents living with HIV/AIDS.

\section{Limitations and strength of the study}

The study information was collected from adolescents living with HIV aged 14-19 years and willing to be interviewed with more being selected from health facilities with high populations which could have caused a selection bias.

During the study, some of the respondents were faced with stigma and this led to their failure to participate in the study which was addressed through the use of verbal consent and assurance of anonymity by not including respondents names or particulars on the forms and among all centres none had the required sample size for the researcher to carry out his study from the same centre and took a lot of the researchers time to identify healthcare facilities to conduct his study from.

More to this is the bureaucracy of healthcare facilities to allow the researcher to conduct his study from there were many centres in Kampala PNFPs wanted exorbitant fees to be paid to their research committees for consideration.

Since data collection was through self-reporting, honesty of the responses could not be guaranteed since these were matters related to one's sex life and some people have stigma attached to their sexual behaviours.

The nature of tradition and community involvement required people to discuss sexual issues in privacy and owing to the fact that interviews were conducted in local language, Luganda were need arose, the study team had to ensure that socio-cultural aspects are given a priority. 


\section{Conclusion}

Almost all the respondents were aware of their HIV positive status with many of them being disclosed to when they were older than 11years and more than ahalf of them disclosed to by healthworkers.

Males, those living with parents and those disclosed to by a parent or relative were highly likely to know their HIV status earlier when they are 14 years or younger.

Slightly more than a half of the sexually active respondents had disclosed their HIV status to their partners with many of them giving the main reason for disclosure as loving their spouses. $84.3 \%$ of those who reported to have disclosed, were of the same HIV status as their partners and males had a high likelihood of having sexual partners of the same HIV status.

Females had a high likelihood of having ever been in a sexual relationship, adolescents living with HIV in urban areas were highly likely not to be in a sexual relationship. Females and adolescents older than 17 years had a higher likelihood of being sexually active.

$47.7 \%$ of these adolescents living with HIV had ever been in a sexual relationship with almost an equal proportion having had actual sexual intercourse and more than a half of them being compeled into sexual activity because of peer pressure.

Those seeking emotional care from a hospital setting (Counsellors and HIV positive group) had a high likelihood of being sexually active.

Condom use was low with the major reason for using condoms being to prevent pregnancy.

Faliure to use condoms was attributed to mainly thinking that the partner was safe and feeling that it was not necessary to use condoms.

Finding reveal that nearly a half of the respondents were abstaining because they felt that they are still young. Among those who were sexually active, many of them used being faithful to their spouse as a measure to prevent re-infection with HIV.

However some of them thought that contraceptives would prevent re-infection and only $12.8 \%$ had more than two sexual partners.

The majority of males $31.7 \%$ had their sexual debut between 15 -16years as compared to majority of females $30.7 \%$ who had theirs between 17-18 years.

\section{Acknowledgement}

I thank God for giving me strength and courage to carry out the study. I am also grateful to the numerous people that have given their support and contributed to the work presented in this study with humble thanks to all the adolescents who participated in this study. Thank you to my supervisor Dr. Proscovia Namuwenge for effectively supporting me; for constantly providing me with positive and valuable advice. Thank you for sharing your knowledge with me and for your excellent supervision and constructive criticism. Thank you for reading through the pages of -muddled thoughts and gently guiding them to coherence.

Kyambogo University, thank you for giving me an opportunity to fulfil the requirements for this academic award.

I am grateful to the data collection team for their willingness to help and their warmth during the process of data collection. In particular, I wish to thank Miss. Margret and Miss. Penninah of Gombe hospital, Miss. Dorah Nantale of Kasawo health centre III, Mr. Ssozi Francis of Nsambya hospital home care, Ssalongo Kagumba and Mr. Kayondo of Luwero health centre IV for the assistance with identification of the study participants and the directors of those health facilities for allowing me to carry-out this study from their facilities.

Special thanks go to Dr. Simon Ssentumbwe, thanks for everything and the staff of Sim's Medical Centre and Dental Clinic; you are one of a kind! To all my friends and classmates, thank you.

To my family, thank you to my parents Mr. and Mrs. Kyesswa for bringing me up to believe I could do this; to my dear Aunt Miss. Leonorah Bulyaba, Jarvice and Dan. And lastly I cannot forget my siblings Joe, Lydia and Deusdedit, and my niece Tendo your patience and encouragement are greatly appreciated.

\section{References}

1. Wikipedia (2012) Human sexual activity. Accessed on 14th November 2012.

2. Jacob (2009) Practice of sex. June 11, 2009. Accessed on 14th November 2012

3. Burris JL, Smith GT, Carlson CR (2009) Relations among religiousness, spirituality and sexual practices. J Sex Res 46: 282-9.

4. United Nations Children's Fund (2012) Progress for Children. A report card on adolescents Number 10, April 2012.

5. Uganda Ministry of Health and ICF International (2011) Uganda AIDS Indicator Survey: Key Findings. Calverton, Maryland, USA: MOH and ICF International 2012 . 
6. Obare F, Kwaak A, Bwibo A, Owuor D, Okoth S, et al. (2010) HIV-positive adolescents in Kenya, Access to sexual and reproductive health services; KIT Development Policy \& Practice; Bulletin 393.

7. Birungi H, Mugisha JF, Nyombi J, Obare F, Evelia H, et al. (2008) Sexual and reproductive health needs of adolescents perinatally infected with HIV in Uganda.

8. Birungi H, Obare F, Namwebya JH, Mohammed I, Gitau M, et al. (2011) Sexual and reproductive health needs of adolescents living with HIV in Kenya.

9. Vujovic M, Meyersfeld S, Struthers H (2011) Support for HIV positive adolescents.

10. Kancheva Landolt NT, Lakhonphon S, Ananworanich (2011) Contraception in HIV-positive female adolescents. AIDS Res Ther 8:19.

11. Gita D, Kawuma E, Luyirika E, Awori M, Sekyondwa M (2009) Experiences of working with Sexually Active HIV positive Adolescents at Mildmay Uganda.

12. Mergui A, Giami A (2011) The sexuality of HIV-infected-adolescents: literature review and thinking on the unthinkables of sexuality. Arch Pediatr 18:797-805.

13. International HIV/AIDS Alliance (2011) Understanding the needs of adolescents living with HIV in Zambia; Supporting community action on AIDS in developing countries.

14. Nyaradzayi G (2011) Reproductive health for HIV-positive adolescents; PERSPECTIVE; Facing the challenge: The State Of The World's Children.

15. Jabulani S (2011) Challenges of living with HIV; Botswana's positive adolescents: Botswana-Baylor Children's Clinical Centre of Excellence.

16. Uganda Demographic and Health Survey (2011) Kampala, Uganda: UBOS and Calverton, Maryland: ICF International Inc. 2012.

17. Shapiro K, Sunanda R (2007) Sexual Health for People Living with HIV. Reprod Health Matters 15: 67-92.

18. ANOVA Health Institute (2011) Sexual and reproductive health for young HIV positive adolescents: the club concept in support groups.

19. Degu G, Tegbar Y (2006)Lecture Notes for Health Science Students;sMethodology; University of Gondar in collaboration with the Ethiopia Public Health Training Initiative, The Carter Center, the Ethiopia Ministry of Health, and the Ethiopia Ministry of Education 2006.

20. Toska E, Cluver LD, Hodes R, Kidia KK (2015) Sex and secrecy; HIV status disclosure affects safe sex among HIV positive adolescents. AIDS Care 1: 47-58.

21. Atukunda R, Atuyambe ML, Kiwanuka N (2016) Sexual risk related behaviour among youth living with HIV in central Uganda. Pan Afr Med J 24 : 49.

22. Mbalinda NS, Kiwanuka N, Lens EE (2015) Correlate of ever had sex among perinatally HIV infected adolescents in Uganda. Reprod Health 12.

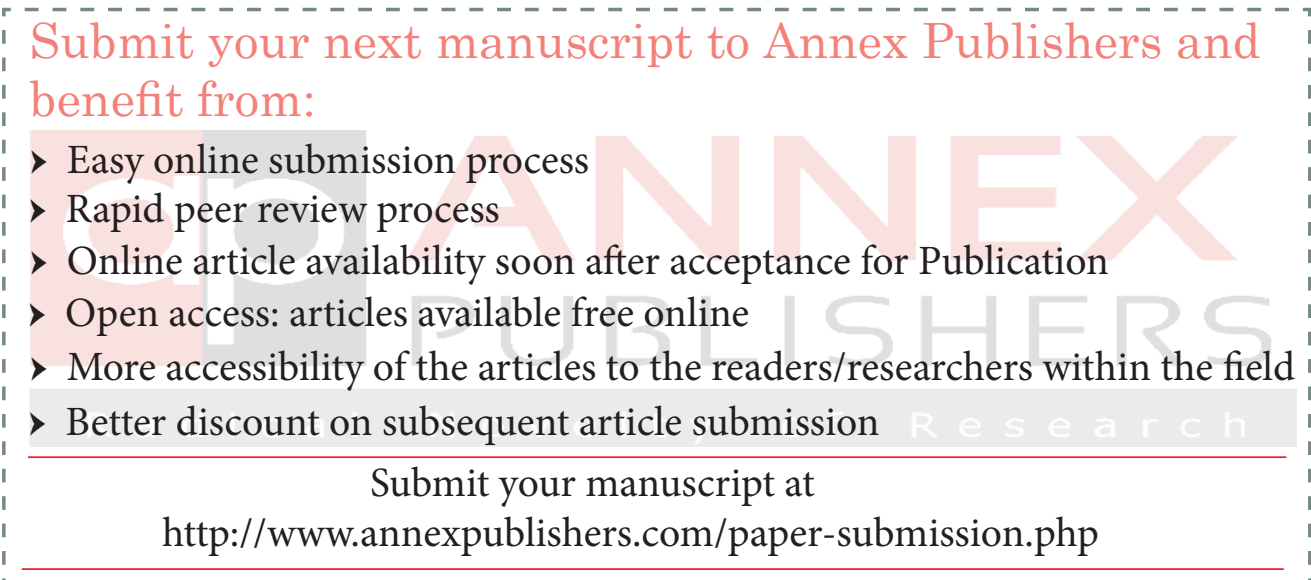

